\title{
Cuidador Familiar \\ de Seqüelados de Acidente Vascular Cerebral: Significado e Implicaçôes
}

| ${ }^{1}$ Fernanda de Freitas Mendonça, ${ }^{2}$ Mara Lúcia Garanhani, ${ }^{3}$ Vera Lúcia Martins |

Resumo: O acidente vascular cerebral (AVC) está entre as principais causas de morte no mundo. Diante das incapacidades impostas pelo AVC, surge o cuidador familiar. O objetivo desta pesquisa foi analisar o significado e as implicações de se tornar cuidador de um indivíduo seqüelado de AVC. Trata-se de um estudo qualitativo, realizado com cinco cuidadores, em Londrina-PR, no período de agosto a dezembro de 2005. Os dados foram coletados por meio de entrevistas semi-estruturadas e submetidos à análise de discurso proposta por Martins e Bicudo. Da análise das entrevistas emergiram sete categorias: voltando-se para o Ser cuidado, descrevendo os cuidados, apresentando as mudanças, o apoio da espiritualidade, compreendendo o significado do cuidado, expressando as necessidades para cuidar e perspectivas para o futuro. Os resultados revelaram que ser cuidador familiar é um fenômeno complexo, que gera nos sujeitos sentimentos de alegria e felicidade concomitantes aos sentimentos de medo, ansiedade e revolta.

\author{
1 Enfermeira, especialista em \\ Saúde Coletiva pela \\ Universidade Estadual de \\ Londrina, mestranda em Saúde \\ Coletiva pela Universidade \\ Estadual de Londrina. Endereço \\ eletrônico: \\ fernandafreitasmendonca@ \\ yahoo.com.br. \\ 2 Enfermeira, docente adjunto \\ no Curso de Enfermagem da \\ Universidade Estadual de \\ Londrina, Doutora em \\ Enfermagem pela Escola de \\ Enfermagem da Universidade \\ de São Paulo. Co-orientadora \\ do trabalho. \\ ${ }^{3}$ Enfermeira, docente no \\ Departamento de Saúde \\ Coletiva da Universidade \\ Estadual de Londrina, Mestre \\ em Saúde Coletiva pela \\ Universidade Estadual de \\ Londrina. Orientadora deste \\ trabalho.
}

> Palavras-chave: acidente cerebrovascular; cuidadores; cuidados domiciliares à saúde. 


\section{Introdução}

$\mathrm{O}$ acidente vascular cerebral (AVC), também denominado ataque cerebral, consiste na perda súbita da função cerebral devido à ruptura do suprimento sanguíneo (SHAWN, 2002) e está entre as principais causas de morte no mundo. No Brasil, o AVC constitui a terceira causa de óbitos entre as patologias clínicas, depois das doenças cardíacas e neoplásicas, e a segunda mais freqüente causa de morbidade entre as doenças neurológicas (CERCI NETO, 2005). No entanto, além do problema do alto índice de mortalidade há um outro, tão sério quanto ele: as seqüelas que ele impóe ao indivíduo sobrevivente.

É nesse contexto que surge um personagem de grande importância para o cuidado do sujeito afetado: o cuidador familiar (LAVINSKY; VIEIRA, 2004). A utilização de familiares para a realização de cuidados a um de seus membros é uma prática antiga e tem-se tornado cada vez mais freqüente, principalmente com o incremento da condição crônica. De acordo com Lavinsky e Vieira (2004), essa realidade é potencializada pela falta de recursos financeiros das famílias para contratar uma empresa que preste cuidados domiciliares ou um profissional particular, tecnicamente preparado para prestar cuidados no domicílio. Diante desse contexto, o cuidado fica na maioria das vezes sob a responsabilidade de um membro familiar que em geral não possui preparo técnico que o permita cuidar do outro sem interferir no cuidado que deve ter consigo próprio.

Percebe-se que a necessidade de cuidado não é demandada somente pelo indivíduo acometido pelo AVC, mas também por aquele que realiza o cuidado. Logo, não há um cuidador absoluto, uma vez que este também necessita ser cuidado, precisa de suporte e apoio para que seu desempenho seja facilitado, compartilhando de algum modo sua tarefa (CAMPOS, 2005).

Para aprofundar essa problemática, apresenta-se este estudo, resultado de uma monografia do curso de Especialização em Saúde Coletiva da Universidade Estadual de Londrina (UEL). A temática acerca dos cuidadores já foi foco de atenção de uma das autoras do estudo, através de uma pesquisa que investigou as famílias que possuíam doentes crônicos. Durante essa experiência, identificou-se que os doentes crônicos não eram os únicos a demandarem cuidados, mas também aqueles que assumiam a função de cuidador. Diante de tal vivência, indagamos: o que é ser cuidador familiar? Que mudanças este cuidador vivencia? Quais são suas necessidades? 
No intuito de buscar a resposta a essas questôes, estabelecemos como objetivo desta pesquisa analisar o significado e as implicações de se tornar cuidador de um indivíduo seqüelado de AVC.

\section{Trajetória metodológica}

Utilizou-se abordagem qualitativa, exploratória e descritiva que favoreceu a exploração das experiências dos familiares que cuidavam de pessoas portadoras de seqüelas de AVC. Segundo Minayo (1994), a pesquisa qualitativa se preocupa com o nível de realidade que não pode ser quantificado; sua abordagem aprofundase no mundo dos significados das ações e das relações humanas.

$\mathrm{O}$ estudo foi realizado no município de Londrina-PR, no período de agosto a dezembro de 2005, com cuidadores familiares de indivíduos seqüelados de AVC, pertencentes à área de abrangência da Unidade de Saúde da Família (USF) Vila Casoni. O critério para inclusão no estudo foi ser familiar cuidador do indivíduo com seqüelas de AVC, ter algum grau de parentesco, mas não necessariamente por laços de consangüinidade. O número de entrevistados foi determinado pela exaustão das informações coletadas, o que resultou na participação de cinco cuidadores.

Como instrumento de coleta de dados foi utilizada a entrevista semi-estruturada, conduzida a partir de um roteiro onde estavam registradas as seguintes questôes geradoras de diálogos:

- O que significa para você cuidar de um familiar?

- Quais mudanças ocorreram em sua vida após você se tornar cuidador?

- Quais necessidades você vivencia para promover o cuidado de seu familiar?

- Quais dificuldades você enfrenta enquanto cuidador?

As falas dos participantes foram gravadas e transcritas na íntegra; após a leitura, foram retirados os vícios de linguagem e feita a correção ortográfica para maior proteção dos participantes da pesquisa.

Para a análise das entrevistas, foi utilizada a análise de discurso proposta por Martins e Bicudo (1989), que abrange dois momentos: no primeiro, foi feita a análise individual ou ideográfica que consiste na leitura das entrevistas, sem buscar ainda qualquer interpretação, com o objetivo de se chegar a um objetivo geral do que será dito pelos sujeitos. Depois de obtidos os sentidos, destacaram-se as unidades de significado, focalizando as questões propostas neste estudo. Após a identificação das unidades de significado, estas foram interpretadas. 
No segundo momento foi feita a análise geral ou monotética, que consiste na compreensão e articulação dos diversos casos individuais como exemplos particulares em algo mais geral. Nesta etapa ocorreu a releitura das entrevistas, em seguida, tomando as unidades de significados interpretadas dos discursos individuais, realizaram-se aproximação e convergências e divergências presentes. Essa aproximação, buscando as evidências entre as unidades de significado, possibilitou a construção de sete categorias que configuram a estrutura do fenômeno estudado. Neste artigo iremos apresentar apenas a análise geral construída a partir das sete categorias.

Os princípios éticos que nortearam esta pesquisa estão contemplados na Resolução o 196/96, que regulamenta a pesquisa envolvendo seres humanos (BRASIL, 1996). Todos os entrevistados foram informados sobre a pesquisa e assinaram o termo de consentimento livre e esclarecido. O projeto de pesquisa foi aprovado pelo Comitê de Ética e Pesquisa da Universidade Estadual de Londrina.

\section{Apresentando a produção de conhecimento}

A primeira cuidadora $(\mathrm{C} 1)$ tinha 44 anos de idade, ensino médio completo e três filhos, sendo um deles de apenas quatro anos, e cuidava de seu esposo havia mais de três anos. A segunda cuidadora (C2) tinha 72 anos de idade, ensino fundamental completo, três filhos e cuidava do ex-esposo havia mais de um ano. A terceira cuidadora (C3) tinha 50 anos de idade, ensino fundamental incompleto, dois filhos e cuidava da mãe havia dois meses. O quarto cuidador (C4) tinha 37 anos, ensino médio completo, era solteiro e cuidava de sua mãe havia dez anos. A quinta cuidadora (C5) tinha 77 anos de idade, ensino fundamental incompleto, era desquitada e cuidava do segundo marido havia um ano.

Dos discursos dos cinco cuidadores, após análise e interpretação, emergiram sete categorias, as quais configuram a estrutura do fenômeno de ser cuidador familiar. Elas são desenvolvidas a seguir.

\section{A primeira categoria: voltando-se para o Ser cuidado}

Através da interpretação dos discursos foi possível perceber a necessidade de o cuidador familiar falar sobre o Ser cuidado. Ao se voltar para o Ser cuidado, o cuidador relembrou os momentos anteriores ao adoecimento deste: "Uma pessoa ativa do jeito que ela 
era...” (C1); “[...] ele foi uma pessoa muito trabalhadora, inteligente [...]. Ele foi um homem muito esperto, conheceu todo o mundo, viajou por todo mundo, trabalhou de segurança, muito esperto, muito trabalhador" (C5).

O cuidador familiar também discorreu sobre como o Ser cuidado adoeceu: "Assim, 10 dias depois que meu pai faleceu aconteceu isso (sua mãe teve o AVC). Então foi um golpe forte desse que a deixou do jeito que ela está" (C4).

A seguir encontramos falas que retratam o aparecimento da doença como algo repentino, que está além da possibilidade de escolha do indivíduo: "É o mesmo que uma criança que não pede para nascer. E a pessoa que fica doente é a mesma coisa, ele não pediu para ficar doente" (C1).

Podemos perceber que o cuidador reflete sobre a não-responsabilidade pelo processo de adoecimento, mas que esse é por vezes imposto - tanto que compara o fato de ficar doente com o nascimento de uma criança, a qual não escolhe nascer, portanto ninguém escolhe ficar doente. A postura dessa cuidadora nos leva a refletir sobre o fato de as pessoas ainda não compreenderem a determinação do processo saúde-doença e não se sentirem responsáveis pela própria saúde.

Ainda explorando essa categoria, os cuidadores também expressaram as manifestações do Ser cuidado perante as seqüelas impostas pelo AVC: “[...] Ele está muito bravo por causa da doença... Às vezes ele xinga" (C5); “Às vezes parece que ela desiste, desanima de fazer os exercícios e tudo" (C4).

Diante desses discursos, verifica-se a presença da revolta e do desânimo entre os sentimentos dos Seres cuidados. Essas manifestações de desânimo e revolta surgem, pois o desejo de sentir-se saudável - inerente ao ser humano - entra em conflito com as limitações impostas pelo AVC.

\section{A segunda categoria: descrevendo os cuidados realizados}

O cuidado é algo essencial à sobrevivência do ser-humano e é necessário não apenas durante a infância, mas também na vida adulta, sobretudo quando a doença está presente (CAMPOS, 2005).

Por meio da análise de alguns discursos, percebe-se que o cuidado dispensado ao Ser cuidado se apresenta de várias formas. Elsen (2002), ao explorar o conceito de cuidado familial, afirma que este pode ser reconhecido por meio de alguns atributos, dentre os quais a proteção, caracterizada por medidas que visem a garantir a segurança física, emocional e social do grupo familiar. Colliére, citado por Andrade 
e Rodrigues (1999), define essas medidas como sendo aqueles cuidados cotidianos ou habituais, cuja função é sustentar a vida.

As verbalizações de alguns cuidadores, ao descreverem as ações de cuidado que realizam, denotaram a presença dessa forma de cuidado: "Eu faço tudo para ele, lavo tudo, faço tudo. Levanto duas a três vezes na noite [...]. Faço a comida do jeito que ele gosta [...]. Eu troco ele" (C5); "A gente tem que ajudar minha mãe a sentar na cama, virar na cama, sentar, dar banho, tudo é a gente que faz" (C3); "Ele é uma pessoa assim [...]. Ele não se alimenta, se eu deixar na vontade dele, ele não se alimenta, no caso eu tenho que servir o almoço para ele, eu dou na boca dele então ele come tudo [...] (C1).

O cuidado também se expressa pelo empenho dos cuidadores em realizar as atividades tidas como necessárias para recuperação do ser cuidado: "A gente a levanta, põe de pé, a gente faz o possível. Até de noite a gente senta ela, porque é o bem dela que a gente quer" (C3).

Elsen (2002) denomina essa forma de cuidado como promoção para a vida e bem-estar, que objetiva impulsionar a vida de cada um dos membros da família. Ele se realiza ao propiciar condiçôes adequadas que favoreçam o desenvolvimento das potencialidades de cada indivíduo.

\section{A terceira categoria: apresentando as mudanças}

Tornar-se cuidador familiar é uma tarefa que provoca muitas mudanças na vida do sujeito que assume essa função. Andrade e Rodrigues (1999), ao realizarem um estudo sobre cuidadores familiares de idosos sequelados de AVC, concluíram que a demanda de cuidados ao idoso com AVC, seja ele de qualquer natureza, causará impacto profundo na vida social, física e econômica do cuidador. Uma das mudanças ocorridas na vida dos cuidadores foi o isolamento social: “[...] Estou sem liberdade [...]. Porque eu não saio. Por exemplo, tinha dias de sábado que nós íamos para a chácara [...]. Eu agora não posso, só saio quando é preciso, por exemplo, para ir ao banco, à prefeitura [...]. Então mudou [...]" (C5).

Diante desse relato, percebe-se que a cuidadora vivencia o isolamento social. Bocchi (2004) identificou que a perda do companheiro é fator determinante do isolamento social. Ainda segundo esse autor, a sobrecarga de atividades também exerce influência no isolamento social. Isso se comprovou na verbalização desse cuidador: 
Eu perdi de certa forma a minha liberdade para sair, se desligar um pouco. Eu tenho aquela obrigação de ficar sempre, todo dia dentro de casa, limpando, lavando, cozinhando, passando, essas coisas. Eu deixo até de jogar bola, tem hora que não dá para deixar ela sozinha, tenho que ficar. Isso me prejudica por causa do trabalho, não dá para ser registrado [...]. (C4)

Observa-se que o cuidador é privado de suas atividades de lazer e de trabalho fora do lar acarretando em uma ruptura no seu convívio social.

Outra mudança relatada pelos cuidadores foram os prejuízos na saúde física:

[...] Eu não durmo direito [...]. Tem noites assim [...]. De passar a noite inteira [...]. No outro dia fico atolada, Porque daí largo todas as outras coisas. Eu continuo fazendo um pouco de tudo, mas não tenho aquele rendimento [...]. Tenho problemas de coluna, nos pés [...]. (C3).

De vez em quando eu me sinto cansada eu quero dormir e ele não deixa. Para você ver, eu estava gorda [...] eu emagreci! Sabe? Porque de manhã ele quer que eu levante. Às vezes eu fico cansada de manhã quero dormir e não consigo dormir direito [...]. Tenho uma dor no joelho de vez em quando [...] (C5).

Esses relatos revelam alguns prejuízos na saúde do cuidador: o cansaço, prejuízos no sono e alguns problemas físicos associados ao esforço contínuo. Esse resultado corrobora os achados de Bocchi (2004), o qual detectou o cansaço e distúrbios no sono como os mais freqüentes entre os cuidadores familiares. No estudo de Andrade e Rodrigues (1999), os problemas físicos ligados ao esforço contínuo também apareceram. Segundo esses autores, os problemas associados ao esforço contínuo resultam do acúmulo de responsabilidades que o cuidador assume. Além disso, vale ressaltar que esses problemas são também oriundos do despreparo do cuidador em assumir o cuidado de um familiar. Cabe salientar o papel dos serviços de saúde em apoiar o cuidador familiar em suas necessidades. Chagas e Monteiro (2004), ao realizarem estudo sobre educação em saúde com pacientes vítimas de AVC, identificaram que a família, sobretudo o cuidador, deve ser alvo também dos cuidados oferecidos pelos serviços de saúde.

\section{A quarta categoria: o apoio da espiritualidade}

A espiritualidade pode ser compreendida de várias formas. Tal compreensão depende da concepção de cada pessoa sobre si mesma, sobre os outros e sobre tudo que a cerca (LUZARDO; WALDMAN, 2004). Independentemente da 
forma como cada pessoa entende a espiritualidade, esta, em geral, está associada à busca de um amparo.

A pessoa quando adoece, ou quando vivencia o adoecimento de um familiar, convive com situações de sofrimento, de desequilíbrio e é nesse momento que a espiritualidade emerge, amparando o sujeito no contexto de instabilidade. A importância da espiritualidade para suportar o adoecimento do ser cuidado fica clara nos relatos a seguir: "A gente precisa [...] de Deus, de oração, de força..." (C3); e "Em primeiro lugar eu preciso de Deus na minha vida, força..." (C1). A presença da espiritualidade como apoio para enfrentar o adoecimento também foi encontrado no estudo de Cecagno, Souza e Jardim (2004).

A espiritualidade atua na vida das pessoas não apenas como um alicerce para suportar os momentos difíceis, mas também influencia a forma como elas concebem o cuidado. Por mais difícil que seja cuidar de um familiar, tanto pela sobrecarga de atividades como pelas profundas mudanças que tal função provoca na vida do cuidador, uma cuidadora afirmou não se sentir no direito de reclamar, pois, segundo ele, estaria pecando: "Se eu reclamar de alguma coisa eu vou pecar" (C2).

A espiritualidade trouxe também para uma cuidadora a sensação de conformidade com as mudanças que o cuidado lhe propiciou: "Eu não tenho liberdade, mas para mim não faz diferença. Eu já tive minha mocidade, hoje eu estou velhinha. Eu fico em casa [...]. Graças a Deus eu estou conformada" (C5).

Aceitar a vontade de Deus é uma das tarefas mais difíceis para o devoto; entretanto, essa dificuldade é amenizada pela fé, isto é, pela certeza de que haverá recompensa pelo sofrimento vivenciado. Sendo assim, os cuidadores suportam com paciência todas as implicações do fenômeno de ser cuidador (WALDMAN; LUZARDO, 2004).

\section{A quinta categoria: compreendendo o significado do cuidado}

$\mathrm{O}$ ato de cuidar significa vivenciar uma diversidade de sentimentos. Tais sentimentos são em geral ambivalentes. A diversidade de sentimentos se justifica pelo intenso envolvimento afetivo proporcionado pelos laços familiares dos sujeitos envolvidos na relação cuidador-Ser cuidado (LAVINSKY; VIEIRA, 2004). Corroborando a afirmação desses autores, os sujeitos da pesquisa se mostraram envoltos de um misto de sentimentos. O sentimento de amor foi manifestado pelos cuidadores isso porque cuidar implica amar como condição prévia; assim sendo, o ato de 
cuidar seria a materialização do amor (CAMPOS, 2005): “[...] a gente cuida com amor" (C3); e "[...] a gente faz com amor". (C1)

Sentimentos de bem-estar, de alegria, de gratificação e prazer em cuidar também foram manifestos pelos cuidadores: "É tão bom a gente poder atender a uma pessoa, ajudar. É melhor eu poder ajudar a cuidar de alguém do que eu precisar de cuidado. Eu me sinto muito bem, muito feliz [...]. De poder estar fazendo alguma coisa para ajudar" (C2).

Teixeira (1998) postula que, além dos sentimentos de estresse e desgaste vivenciados pelo cuidador, este pode sentir também prazer, satisfação quando se envolve produtivamente em suas tarefas e consegue bons resultados.

$O$ cuidado tem sido a forma encontrada pelos filhos de retribuir o cuidado que outrora receberam dos pais: "É uma troca de favor, né? Do que ela fez por mim durante tanto tempo" (C4); "A mãe sofreu pela gente, eu acho que ela merece nosso esforço" (C3). Lavinsky e Vieira (2004) relatam que os laços familiares fortalecem a oportunidade de retribuir os cuidados recebidos pelo cuidador em tempos anteriores ao AVC do familiar.

O cuidado despertou também, nos cuidadores, sentimentos difíceis de serem vivenciados. Campos (2005) revela que lidar com o sofrimento de uma pessoa implica se identificar com a pessoa que sofre e sofrer junto com ela, ou seja, conviver com o sofrimento gera sofrimento. $\mathrm{O}$ medo foi um sentimento expresso por alguns cuidadores: "A gente tem receio que de repente possa dar um derrame, por causa daquela tensão nervosa que ela sente, de querer melhorar, voltar a fazer todas as coisas que ela fazia e não conseguir fazer” (C3); “[...] eu tenho muito, muito medo [...]" (C1).

O sentimento de medo, em geral, está relacionado ao medo da piora do estado de saúde e da morte. Resta e Bubó (2004), em estudo focando a cultura e as formas de cuidar, encontraram também o sentimento de medo entre os cuidadores. Alguns cuidadores relataram sentir pena do ser cuidado, devido ao sofrimento e as incapacidades presentes no familiar: "[...] Eu tenho muita pena" (C1); "A gente tem muita pena dela, por que ela está sofrendo...” (C3); “[...] eu olho para ele e fico com pena [...]. A gente o vê assim amarrado, dá muita pena” (C5).

O sentimento de impotência diante das incapacidades e do sofrimento também esteve presente nos cuidadores e é citado no estudo de Centa, Carneiro e Pinto (2003): “[...] você queria estar tirando aquela dor, você queria estar aliviando o sofrimento da 
pessoa. Tudo que você fizer ainda é pouco" (C3); "É para mim é chato ver ela nessa situação e não poder fazer nada, a gente fica impotente [...] (C4).

Surgiu também nos cuidadores o sentimento de revolta. Esse sentimento emerge devido à dificuldade de o ser humano enfrentar e aceitar as mudanças impostas pela vida; "Olha, no começo a gente fica meio assim, meio revoltada" (C2); "[...] Eu fico revoltado com essa situação que aconteceu... Para ela ficar desse jeito. Então eu fico revoltado porque eu não posso fazer nada” (C3).

O cuidado, para alguns cuidadores, é tido como uma obrigação: "Eu não sei se é uma obrigação! Ele é pai dos meus filhos, ele também ajudou a educar a minha família” (C2); “[...] Eu vou fazer o que, né? É meu dever eu acho, eu vivo com ele há 43 anos" (C5).

Analisando esses relatos, percebe-se que as cuidadoras se sentem na obrigação de cuidar devido a um vínculo que mantêm ou mantiveram com o ser cuidado. $\mathrm{O}$ cuidado como obrigação está relacionado ao cumprimento de regras que se contrapóe à vontade do cuidador.

O cuidado a um familiar foi classificado como uma tarefa difícil. A dificuldade expressada pelos cuidadores está relacionada a diversos fatores, dentre eles, o fato de assumirem novas responsabilidades, o desgaste físico e o estresse.

Andrade e Rodrigues (1999) também encontraram que o cuidado está associado a uma rotina cansativa e frustrante, pois não se tem um resultado efetivo na recuperação. Eles ainda reforçam que essa associação do cuidado a algo cansativo e estressante pode ser compreendida quando se considera a senescência, período em que a pessoa não apresenta grandes mudanças em seu estado físico e mental. Os seguintes relatos apresentam algumas dificuldades dos cuidadores: "Essa situação que ele está é a primeira vez que eu enfrento. Ele faz xixi na bolsa, faz ... Cocô também, então é muito difícil viu, difícil mesmo" (C5); “[...] É uma coisa que é meio desgastante um pouco, né?” (C4); "Você fica meio estressada um pouco, fica!" (C3).

\section{A sexta categoria: expressando as necessidades para cuidar}

Nesta categoria, os cuidadores expressam suas necessidades, bem como aquilo que, segundo eles, é importante para promover o cuidado de forma saudável. A valorização e a necessidade de um auxílio, isto é, de alguém para dividir as 
responsabilidades de cuidar, foi manifestada pelos cuidadores: “[...] Às vezes eu preciso de uma pessoa para me ajudar a colocar ele na cadeira, para trocar a cama, a necessidade de uma pessoa para me ajudar" (C5). E ainda:

Não dá para ficar caindo só sobre as minhas costas. É aquela coisa se todo mundo pudesse ficar cuidando dela, ficando de olho nela, assim na hora do almoço, na hora que eu preciso sair. Se pudesse ter alguém aqui sempre nesse tipo de horário para eu trabalhar eu não esquentaria a cabeça... (C4)

Assumir o cuidado de um familiar sozinho não é uma tarefa fácil, pois além de os cuidadores lidarem com uma diversidade de sentimentos, eles se vêem obrigados a agregar novas atividades a sua rotina de vida. Nesse contexto merece destaque o apoio do suporte social. O suporte social construído no campo da psicologia social e saúde comunitária se refere às relações interpessoais, grupais ou comunitárias que emprestam ao indivíduo um sentimento de proteção e apoio capaz de propiciar bem-estar psicológico e redução do estresse (CAMPOS, 2005). A rede social natural básica é a família nuclear; no entanto, os parentes, vizinhos, amigos, serviços de saúde também constituem a extensa rede de suporte social.

Uma cuidadora reconheceu na presença dos amigos algo importante para enfrentar as mudanças impostas pela função de cuidador: "Eu tenho muitos amigos, não desanimo" (C5).

Estudo desenvolvido com idosos e seus cuidadores verificou que eles têm necessidades de apoio e ajuda da família, de ter atividades sociais, de satisfazer suas próprias necessidades como ser humano (LUZARDO; WALDMAN, 2004). Essas necessidades também foram expressas por alguns cuidadores. No relato a seguir, denota-se a necessidade de a cuidadora receber a compreensão da família: "A gente precisa [...] do entendimento da família também, né? Eles cobram mais da gente, porque a gente está cuidando" (C3).

O desejo de satisfazer a necessidade de vida social e lazer emergiu como um grito por este cuidador.

[...] eu tenho que tocar meu caminho também, eu tenho que sair, tenho que namorar, tenho que arrumar trabalho. Desses tempos para cá, eu só venho fazendo bico. Meus irmãos estão vivendo a vida deles, cada um casou, meu irmão mais novo casou, minha irmã casou e está cuidando da vida dela e eu estou ficando! Você deixa de lado muita coisa que você poderia estar fazendo se não tivesse que ficar aqui com ela. Eu poderia estar com uma vida totalmente diferente. (C4) 
Por outro lado, há cuidadores que consideram importante o total despojamento de si para cuidar do outro: "Então eu acho que [...] por mais que eu tenha alguma necessidade eu não vejo assim. Eu vejo só o lado dela, eu não me preocupo comigo" (C3); "Eu tenho que cuidar dele, dedico minha vida só para ele" (C5).

Essa falta de atenção consigo mesmo é uma atitude de não-cuidado, pois a nãopercepção das próprias necessidades faz com que os cuidadores jamais busquem satisfazê-las. Bocchi (2004) identificou que os cuidadores se viam surpresos ao serem questionados sobre como o cuidado a um familiar os afetava física e emocionalmente. Nesse sentido, percebe-se que o nível de envolvimento com o Ser cuidado é tão profundo que o cuidador não percebe suas próprias necessidades.

A saúde também foi expressa pelos cuidadores como algo importante para promover o cuidado: "Meu desejo é saúde, que Deus me dá. Tem coisas que a gente tem pouco. Mas Deus dando saúde para mim está tudo resolvido" (C2).

A estabilidade financeira também surge como uma necessidade. Ao passo que uns cuidadores valorizam sua boa condição econômica, outro lamenta e comenta sobre as limitações impostas pela baixa renda familiar: "[...] graças a Deus eu tenho condições se eu não tivesse eu acho que seria pior...” (C1); "Eu faço compra no mercado, eu tenho tudo graças a Deus. Se eu quero alguma coisa diferente eu vou ao mercado trago, compro não me falta nada" (C 5); “[...] contratar alguém para ficar com ela não dá, está muito caro" (C4).

Vários estudos, como de Bocchi (2004), Marcon et al. (2004), Odebrecht, Gonçalves e Meirelles (2003), relataram o impacto que a doença provoca na estabilidade econômica. Segundo esses estudos, a presença de um familiar portador de doença crônica acarreta profundas limitações econômicas para a família. Isso porque a doença crônica implica o uso contínuo de medicaçóes, as quais nem sempre estão disponíveis nos serviços públicos de saúde. Além do mais, pode haver redução no número daqueles que contribuem com a renda familiar, visto que a função de cuidador, às vezes, exige o abandono do emprego.

Os cuidadores também revelaram como necessária a presença de algumas atitudes para promover o cuidado de seus familiares, tais como paciência, coragem e motivação: "Então a gente só tem como continuar a incentivar, para ela acreditar que vai melhorar um dia [...]. A gente tem que ser paciente" (C4); "Eu tenho muita coragem, eu tenho que vencer, eu tenho que cuidar" (C5). 
O cuidado realizado por um familiar foi valorizado por uma cuidadora: "É muito importante eu cuidar, do que ficar pensando como é que ela está lá só [...]. Com outra pessoa que é uma pessoa estranha" (C3). Essa postura de valorização do cuidado familiar também foi encontrada no estudo de Odebrecht, Gonçalves e Meirelles (2003). Segundo esses autores, tal valorização está associada ao desejo do cuidador de envolver a família no processo de cuidado, de forma que ele se sente à vontade em dividir essa responsabilidade apenas com alguém da própria família.

\section{A sétima categoria: perspectivas para o futuro}

Nesta categoria, os cuidadores expressaram suas perspectivas quanto à evolução do estado de saúde do Ser cuidado. Uma cuidadora pensou na possibilidade da piora do quadro: “[...] se Deus me livre eu precisar pagar uma pessoa eu vou ter que contratar uma pessoa do sexo masculino, um homem forte que possa me ajudar a auxiliar ele [...] (C1).

Os demais cuidadores apresentaram esperança e fé na recuperação do Ser cuidado: "Assim é bem devagar a recuperação dela, mas graças a Deus já está melhor, ela está melhorando" (C4); “Tenho fé em Deus e vejo que a recuperação dela já está resultado. A gente tem fé em Deus que ela vai conseguir se recuperar" (C3).

Os relatos acima evidenciam a singularidade do fenômeno de ser cuidador, uma vez que, além de provocar uma ampla variedade de sentimentos, também desperta nos cuidadores expectativas distintas quanto à evolução do Ser cuidado.

\section{Considerações finais}

O AVC é uma patologia crônica que acomete não apenas o indivíduo, mas toda a família, sobretudo aquele familiar que assume a função de cuidador. Por meio das verbalizaçôes dos sujeitos, percebemos que ser cuidador familiar é uma tarefa árdua, difícil, que limita a vida do cuidador.

Entretanto, em meio a esse universo de dificuldades, descobrimos que ser cuidador também implica sentir-se bem e feliz. Diante dessa ambivalência de sentimentos, percebemos que cuidar de um familiar é uma tarefa complexa e singular a cada cuidador, que gera nos mesmos distintas formas de compreensão do cuidado.

As necessidades e as implicações relatadas pelos participantes da pesquisa revelam o quanto esse grupo de "heróis" necessita de atenção por parte dos serviços 
de saúde e da sociedade, sobretudo atualmente, quando a doença crônica constitui um dos mais relevantes problemas de saúde pública.

Os achados da pesquisa mostram que ainda há muito que se conhecer sobre o fenômeno de ser cuidador, sendo necessária a realização de mais estudos que visem a identificar as necessidades vivenciadas pelos cuidadores familiares.

Acreditamos que a produção de conhecimento acerca dessa temática contribuirá com as equipes de saúde, uma vez que munidas de tais informaçôes, poderão assistir as famílias, buscando satisfazê-las em suas necessidades. Ou seja, precisamos despertar o cuidado nos profissionais de saúde.

\section{Referências}

ANDRADE, O. G. de; RODRIGUES, R. A. P. O cuidado familiar ao idoso com seqüela de acidente vascular cerebral. Revista Gaúcha de Enfermagem. Porto Alegre, v. 20, n. 2, p.90-109, jul. 1999.

BOCCHI, S. C. M. Vivenciando a sobrecarga de vir-a-ser um cuidador familiar de pessoa com acidente vascular cerebral (AVC): uma análise do conhecimento. Revista Latino-Americana de Enfermagem. São Paulo, v. 12, n. 1, p. 115-121, jan./fev. 2004.

CAMPOS, E. P. Quem cuida do cuidador. Petrópolis: Vozes, 2005.

CECAGNO, S.; SOUZA, M. D. de; JARDIM, V. M. da R. Compreendendo o contexto familiar no processo saúde-doença. Acta scientiarum. Health sciences. Maringá, v. 26, n. 1, p. 07-112, jan./ jun. 2004.

CENTA, M. L.; CARNEIRO, F. A.; PINTO, M. N. G. H. R. Experiências vivenciadas pelos familiares-cuidadores. Ciência, cuidado e saúde. Maringá, v. 2, supl., p. 87, 2003.

CERCI NETO, A. Neurology. Disponível em: <http://www.medstudents.com.br/neuro >. Acesso em: 22 jun. 2005.

CHAGAS, N. R.; MONTEIRO, A. R. M. Educação em saúde e família: o cuidado ao paciente, vítima de acidente vascular cerebral. Acta scientiarum. Health sciences. Maringá, v. 26, n. 1, p. $193-$ 204, jan./jun. 2004.

CONSELHO NACIONAL DE SAÚDE (Brasil). Resolução no 196/96 sobre pesquisa envolvendo seres humanos. Brasília, 1996.

ELSEN, I. Cuidado familial: uma proposta inicial de sistematização conceitual. In: ELSEN, I. et al. $O$ viver em familia e sua interface com a saúde e a doença. Maringá: UEM, 2002. p. 11-24.

GOLDIM, J. R. Manual de iniciação à pesquisa em saúde. Porto Alegre: Dacasa, 2000. 
LACERDA, M. R.; OLINISK, S. R. O familiar cuidador e a enfermeira: desenvolvendo interação no contexto domiciliar. Acta scientiarum. Health sciences. Maringá, v. 6, n. 1, p. 239-248, jan./jun. 2004.

LAVINSKY, A. E.; VIEIRA, T. T. Processo de cuidar de idosos com acidente vascular encefálico: sentimentos dos familiares envolvidos. Acta scientiarum. Health sciences. Maringá, v. 26, n. 1, p. 41-25, jan./jun. 2004.

LUZARDO, A. R.; WAIDMAN, B. F. Atenção ao familiar cuidador do idoso de Alzheimer. Acta scientiarum. Health sciences. Maringá, v. 26, n. 1, p. 135-145, jan./jun. 2004.

MARCON, S. S. et al. Características da doença crônica em famílias residentes na região norte do município de Maringá, Estado do Paraná: uma primeira aproximação. Acta scientiarum. Health sciences. Maringá, v. 26, n. 1, p. 83-93, jan./jun. 2004.

MARTINS, J.; BICUDO, M. A. V. A pesquisa qualitativa em psicologia: fundamentos e recursos básicos. São Paulo: Morais, 1989.p. 110.

MINAYO, M. C. de S. Ciência, técnica e arte: o desafio da pesquisa social. In: MINAYO, M. C. de S. (Org.). Pesquisa social: teoria, método, criatividade. Petrópolis: Vozes, 1994, p. 9-27.

ODEBRECHT, C.; GONÇALVES, L. de O.; MEIRELLES, S. B. C. Caracterização dos cuidadores de idosos familiares quanto a exigências físicas e emocionais sofridas. Ciência, Cuidado e Saúde, Maringá, v. 2, supl., p. 129, 2003.

RESTA, D. G.; BUDÓ, M. de L. D. A cultura e as formas de cuidar em família na visão de pacientes e cuidadores domiciliares. Acta scientiarum. Health sciences. Maringá, v. 26, n. 1, p. $53-$ 60, jan./jun. 2004.

SHAWN, M. M. et al. Tratamento de paciente com disfunção neurológica. In: SMELTZER, S. C.; BARE, B. G. Tratado de enfermagem médico-cirúrgica. Rio de Janeiro: Guanabara Koogan, 2002. p. 1562-1601.

TEIXEIRA, M. H. Relação interpessoal: cuidador-idoso dependente/cuidador-família. In: CALDAS, C.P. (Org.). A saúde do idoso: a arte de cuidar. Rio de Janeiro: EdUERJ, 1998. 
Family caregiver of stroke sequel patients: meanings and implications

The brain vascular accident (BVA) is one of the main death causes worldwide. Due to the impairments imposed by the BVA, there is the family caregiver. This work aims to analyze the meaning and implications of being a caregiver of a stroke sequel person. It is a qualitative research, carried out with five caregivers in Londrina-PR, from August to December 2005. Data were collected in semi-structured interviews and were subjected to discourse analysis proposed by Martins and Bicudo. From the analysis of interviews seven categories arouse: turning to the being cared, describing care, presenting changes, spirituality support, understanding the meaning of care, expressing the needs to take care and future perspectives. Results revealed that being a family caregiver is a complex phenomenon, that creates in the subjects feelings of happiness and along with feelings of fear, anxiety and revolt.

> Key words: Brain vascular accident; caregiver; home care. 